\title{
E-Cigarette Use Among University Students in Slovakia
}

\author{
Jana Babjakova 1, Michael Weitzman ${ }^{2}$, Diana Vondrova ${ }^{1}$, Alexandra Filova ${ }^{1}$, Branislav Kollar ${ }^{3}$, \\ Juraj Stofko ${ }^{4}$, Jana Jurkovicova ${ }^{1}$ and Lubica Argalasova ${ }^{1,}$ \\ 1 Faculty of Medicine Comenius University Bratislava, Institute of Hygiene, Spitalska 24, 81372 Bratislava, \\ Slovakia; jana.babjakova@fmed.uniba.sk (J.B.); diana.vondrova@fmed.uniba.sk (D.V.); \\ alexandra.filova@fmed.uniba.sk (A.F.); jana.jurkovicova@fmed.uniba.sk (J.J.) \\ 2 Department of Pediatrics, New York University School of Medicine, 1 Park Avenue, NY, NY 10025, USA; \\ michael.weitzman@nyumc.org \\ $31^{\text {st }}$ Department of Neurology of the Faculty of Medicine of Comenius University in Bratislava and of the \\ University Hospital Bratislava, Mickiewiczova 13, 81369 Bratislava, Slovakia; b.kollar@pobox.sk \\ 4 Institute of Physiotherapy, Balneology and Medical Rehabilitation, The University of St. Cyril and \\ Methodius in Trnava, 91701 Trnava, Slovakia; juraj.stofko@gmail.com \\ * Correspondence: lubica.argalasova@fmed.uniba.sk; Tel.: +421-905-209-114
}

\begin{abstract}
Young adults are more likely to have experimented with electronic cigarettes (EC) and underestimate their risks. The on-line survey adapted from American Survey on Tobacco and Alternative Tobacco Products included questions about the personal use of EC, perceptions about the harms and their role in disease causation, education and cessation training and practices related to classical cigarettes (CC), electronic cigarettes (EC) and alternative tobacco products (ATP). The questionnaire filled in 577 medical students (71.9\% women) from Comenius University in Bratislava, the average age was $23 \pm 2$ yrs. The sample comprised of $486(84.2 \%)$ Slovak and $91(15.8 \%)$ foreign students; 385 were (66.7\%) non-smokers, 111 (19.3\%) ex-smokers and 81 (14\%) current smokers. EC currently use $13.5 \%$ medical students, more males than females $(22.2 \%$ vs $10.12 \%$; OR $2.53,95 \%$ CI 1.55-4.13), more foreign students than Slovak students (24.2\% vs 11.52 ; OR 2.44, 95\% CI 1.41-4.26), more smokers of classical cigarettes than non-smokers (46.9\% vs 8.06\%; OR 10.07, 95\% CI 5.85-17.34). EC seems to be less harmful to $59.97 \%$ students, mostly in the age groups $\leq 24(61.76 \%$ vs $51.49 \%$; OR $1.46,95 \%$ CI 1.03-2.07), $41.25 \%$ of students consider EC to be less addictive, 55.6\% think they do not get enough education on EC during their medical study. The results show the high consumption of tobacco products and the lack of knowledge and awareness among medical students.
\end{abstract}

Keywords: university students; electronic cigarettes (ECs); questionnaire survey; Slovakia

\section{Introduction}

There is an existing general agreement that smoking belongs to one of the worst public health threats. Tobacco use represents an important public health issue worldwide. Particularly in the WHO European Region, where the highest levels of tobacco-use prevalence (over 29\%) have been reported [1]. Tobacco in any form kills more than 8 million people each year and it is the major risk factor for many chronic non-communicable diseases and the leading preventable cause of death worldwide $[2,3]$. Smoking remains a regular bad habit among the majority of those who smoke. Fortunately, considerable progress has been made reducing conventional classical cigarette smoking (CC) among youth in some countries [4,5]. On the other hand, a great number of smokers persist. Overall, more than a quarter of Europeans consume tobacco products [4].

When it comes to alternative tobacco products (ATP), the discussion continues among the common population, scientists, stakeholders, and policymakers; their use has some proponents, but also opponents. Among smoking alternatives, electronic cigarettes (EC) have likely received the 
greatest advocacy, policy, and media attention. However, the popularity of them and public interest is undocumented in many countries. EC are types of electronic nicotine delivery systems (ENDs). Easier availability of the ENDs and its widespread distribution is accompanied by many controversial views. As they are relatively short on the market compared to conventional cigarettes, health effects and consequences are not clear yet, the trends in vaping should continue to be monitored and investigated carefully $[6,7]$.

E-cigarette, electronic cigarette, e-cig (EC) is a product that can be used for consumption of nicotine-containing vapor via a mouthpiece, or any component of that product, including a cartridge, a tank and the device without cartridge or tank [8]. ECs are designed to deliver nicotine, but they contain also propylene glycol or glycerol, flavorings, and other additives, that are handed over to the user via an inhaled aerosol after heating [9]. Many ECs contain misleading information on product ingredients, not only the different amounts of nicotine but also harmful substances: fine/ultrafine particles, cytotoxic substances, harmful metals, carcinogenic tobacco-specific nitrosamines and carbonyls [7]. The new data from Gray [10] demonstrates the impact of device design and materials on toxic metals in different ENDs liquid ( $\mathrm{Cr}, \mathrm{Ni}, \mathrm{Cu}, \mathrm{Zn}$, $\mathrm{Sn}$, and $\mathrm{Pb}$.). Increased metal concentrations in the liquid were followed by elevation in the aerosol. EC use has increased significantly especially among youth $[9,11]$. Vaping is fundamentally different than smoking because it involves the heating of an e-liquid that doesn't contain tobacco, while smoking involves the combustion of tobacco. The National Academy of Sciences, Engineering and Medicine in 2018 released a report stating that while ECs are not without health risks, they are likely to be far less harmful than conventional cigarettes and can help adults to stop smoking [12]. The systematic review suggests that EC use may help to reduce the number of smoked cigarettes as well as to relieve the nicotine withdrawal symptoms [13]. There is substantial evidence among youth (who use ECs at higher rates than adults) that EC use increases the risk of transition to the smoking of conventional cigarettes [12].

The use of these products raises a serious public health concern about the risk for non-smokers to develop nicotine dependence and for current smokers to keep up their dependence [14, 15]. Public Health England has maintained that EC is 95 percent less harmful than CC and has encouraged smokers who can't quit smoking to switch to this less harmful alternative [9], so-called "harm reduction" strategy. This strategy might be again for smokers unwilling to quit but ex- and neversmokers probably have an increased risk by using EC. Because of the relatively few and often small studies, many methodological problems, inconsistencies, and contradictions in results, severe conflicts of interest no solid conclusions can be drawn on the safety of EC. However, they can hardly be considered harmless [7].

Nicotine is a highly addictive substance. After switching from CC to EC the dependence persists [11]. Nicotine certainly stimulates the brain's reward system, it's unknown whether it affects brain development. Young adults are more likely to have experimented with EC and underestimate their risks. Still reminding problems are dual-use of CC and ATP and possible "gateway" to CC smoking. In some studies [16] dual users were significantly more likely to report AEs (vaping-related adverse events) than e-cigarette-only users.

According to the CDC report [17], ECs are not safe for youth, young adults, pregnant women, or adults who do not currently use tobacco products. Recent reports of a death in the US linked to vaping, and of almost 200 cases of lung disease, have caused distress about the widespread use of EC. Vitamin E acetate, an additive to THC-containing e-cigarette is strongly linked to the product useassociated lung injury (EVALI) outbreak. CDC recommends persons not to use THC-containing ECs or vaping products, particularly from informal sources. Recommendation for clinicians, public health practitioners, and the public is to remain vigilant by taking steps to reduce risk, including efforts by clinicians to identify and treat EVALI patients [18]. The use of EC among young adults in Slovakia is not well documented.

The aim of our study is to investigate the use of various tobacco products among medical students, their knowledge and beliefs about CC and ATP, especially EC, perceptions about the risk of CC and ATP, as well as to assess the type of education, and cessation training they received during their study at Faculty of Medicine, Comenius University in Bratislava, Slovakia. As future health care 
providers, medical students will play a key role in health promotion and disease prevention and they should serve as a model for their patients and for the general public as well.

\section{Material and Methods}

This cross-sectional, anonymous online survey was conducted among medical students via the Study Department by sending e-mails containing the survey link. Participants completed the online questionnaire Study on Tobacco and Alternative Tobacco Products (ATP). The questionnaire was adapted from the Tobacco and Alternative Tobacco Products Survey of the School of Medicine, New York University (NYU), based on the methodology and results of three studies (National Youth Tobacco Survey 2011, Global Health Professions Student Survey and A Survey Study on Medical Students' Habits and Knowledge of Waterpipe in a Canadian Medical School). It included questions about the use of CC, EC, perceptions about the harms and their role in disease causation, education and cessation training and practices related to CC and EC [19].

In Slovakia study, we used the same questionnaire translated into the Slovak language in order to obtain comparative results. Questionnaires were available online starting in May 2015. The students were repeatedly encouraged via email to fill in the questionnaire. In this contribution, we focused mainly on the assessment of the EC use in medical students and their opinion and knowledge on electronic cigarettes.

The online questionnaire was completed by 577 medical students from the study program General Medicine at Comenius University in Bratislava, the average age was $23 \pm 2$ yrs. The sample comprised of $486(84.2 \%)$ Slovak and $91(15.8 \%)$ foreign students (residing outside Slovakia and studying in the English language), 415 (71.9\%) women (Table 1). The study sample was selected from 2,194 General Medicine students (all six grades) in the study year 2014/2015. The estimated minimum sample size on a $95 \%$ confidence level was 222 medical students. The response rate was $26.3 \%$ among Slovak and $12.4 \%$ among foreign students.

Table 1. Demographic characteristics of the sample

\begin{tabular}{ccccc}
\hline Characteristics & $\mathbf{N}$ & $\mathbf{\%}$ & $\begin{array}{c}\mathbf{9 5 \%} \mathbf{C I}- \\
\text { Lower bound }\end{array}$ & $\begin{array}{c}\mathbf{9 5 \%} \text { CI - } \\
\text { Upper bound }\end{array}$ \\
\hline $\begin{array}{c}\text { Gender } \\
\text { Women }\end{array}$ & 415 & 71.92 & 68.03 & 75.52 \\
Men & 162 & 28.08 & 24.48 & 31.97 \\
\hline Residence & & & & \\
Slovak & 486 & 84.23 & 80.94 & 87.05 \\
Abroad & 91 & 15.77 & 12.95 & 19.06 \\
\hline Age & & & & \\
$\leq 24$ & 476 & 82.50 & 79.09 & 85.46 \\
$>24$ & 101 & 17.50 & 14.54 & 20.91 \\
\hline Smoking status of CC & & & & \\
Nonsmoker & 385 & 66.72 & 62.69 & 70.53 \\
Former smoker & 111 & 19.24 & 16.15 & 22.74 \\
Current smoker & 81 & 14.04 & 11.36 & 17.20 \\
\hline Smoking status of EC & & & & \\
No & 499 & 86.48 & 83.36 & 16.64 \\
Yes & 78 & 13.52 & 10.89 & \\
\hline
\end{tabular}

CC - classical cigarettes; EC - electronic cigarettes; $\mathrm{N}$ - number of cases; $\mathrm{CI}$-confidence interval

To evaluate the results, we used the methods of descriptive and analytical statistics using statistical package Epi Info ${ }^{\mathrm{TM}}$ software, version 7.1.5.0, Atlanta, GA, USA, and SPSS, version 24 (International Business Machines Corp.; New Orchard Road; Armonk, NY, USA).

\section{Results}


There were 385 (66.7\%) non-smokers, 111 (19.3\%) ex-smokers and 81 (14\%), current smokers, in the study sample. EC currently uses $13.5 \%$ medical students, with a statistically significant intersexual difference (22.2\% males vs $10.12 \%$ females; OR $2.53,95 \%$ CI $1.55-4.13)$. There was also a statistically significant difference in terms of EC smoking among medical students studying in English and in the Slovak language - foreign students were more likely to smoke EC ( $24.2 \%$ vs $11.52 \%$; $\mathrm{OR}=2.44 ; 95 \% \mathrm{CI} 1.41$ to 4.26 ). More EC vapers were among smokers of classical cigarettes than among non-smokers ( $46.9 \%$ vs $8.06 \%$; OR 10.07 , 95\% CI 5.85-17.34) (Table 1 ).

Table 2. Sample characteristics and the use of EC (bivariate analysis)

\begin{tabular}{cccccc}
\hline \multirow{2}{*}{ Characteristics } & \multirow{2}{*}{$\mathbf{N}$} & \multicolumn{2}{c}{ Use of EC \% [95\% CI] } & \multicolumn{2}{c}{ Bivariate analysis } \\
\cline { 3 - 6 } & & No & Yes & OR [95\% CI] & p-value \\
\hline Gender & & & & & \\
Women & 415 & 89.88 & 10.12 & & \\
& & {$[86.46-92.53]$} & {$[7.47-13.53]$} & 2.53 & $<\mathbf{0 . 0 0 1}$ \\
Men & \multirow{2}{*}{162} & 77.78 & 22.22 & {$[1.55-4.13]$} & \\
& & {$[70.59-83.92]$} & {$[16.08-29.41]$} & & \\
\hline
\end{tabular}

\section{Residence}

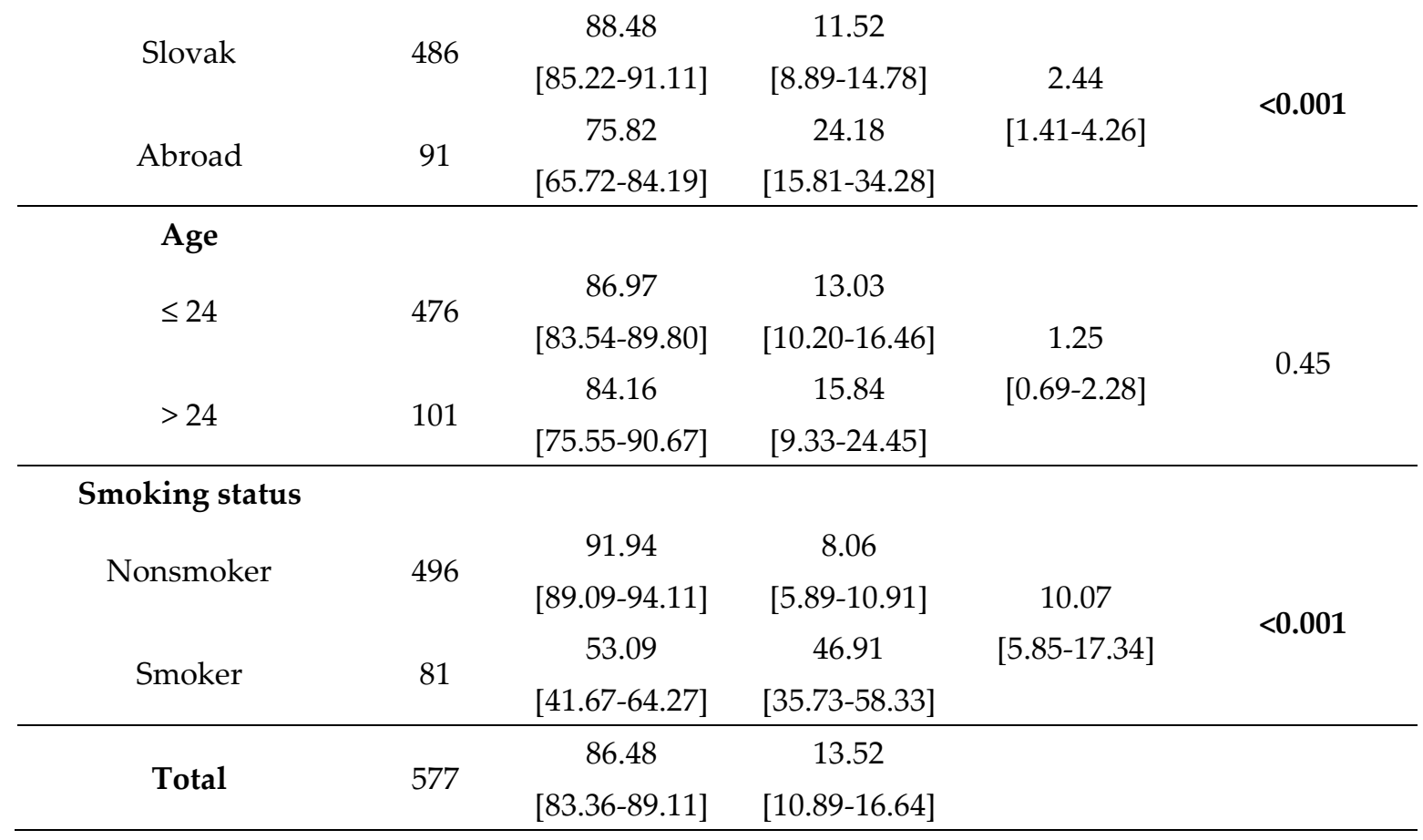

CC - classical cigarettes; EC - electronic cigarettes; $\mathrm{N}$ - number of cases; $\mathrm{OR}$ - odds ratio; $\mathrm{CI}$ - confidence interval

Table 3. Perception of the harmfulness of EC compared to CC (bivariate analysis)

\begin{tabular}{ccccccc}
\hline \multirow{2}{*}{ Characteristics } & $\mathbf{N}$ & \multicolumn{2}{c}{ Opinion about harmfulness \% [95\% CI] } & \multicolumn{2}{c}{ Bivariate analysis } \\
\cline { 3 - 7 } & & harmful & $\begin{array}{c}\text { Equally } \\
\text { harmful }\end{array}$ & $\begin{array}{c}\text { More } \\
\text { harmful }\end{array}$ & $\begin{array}{c}\text { OR } \\
{[95 \% \text { CI }]}\end{array}$ & p-value \\
\hline Gender & & & & & & \\
Women & 415 & 60.24 & 33.01 & 6.75 & & \\
& & {$[55.34-64.95]$} & {$[28.55-37.80]$} & {$[4.61-9.72]$} & 1.19 & 0.12 \\
Men & 162 & 59.26 & 29.63 & 11.11 & {$[0.88-1.62]$} & \\
\hline
\end{tabular}

Residence 


\begin{tabular}{|c|c|c|c|c|c|c|}
\hline Slovak & 486 & $\begin{array}{c}61.11 \\
{[56.60-65.44]}\end{array}$ & $\begin{array}{c}31.48 \\
{[27.41-35.85]}\end{array}$ & $\begin{array}{c}7.41 \\
{[5.31-10.20]}\end{array}$ & 1.36 & \\
\hline Abroad & 91 & $\begin{array}{c}53.85 \\
{[43.08-64.36]}\end{array}$ & $\begin{array}{c}35.16 \\
{[25.44-45.88]}\end{array}$ & $\begin{array}{c}10.49 \\
{[5.40-19.18]}\end{array}$ & [0.94-1.96] & 0.83 \\
\hline \multicolumn{7}{|l|}{ Age } \\
\hline$\leq 24$ & 476 & $\begin{array}{c}61.76 \\
{[57.21-66.12]}\end{array}$ & $\begin{array}{c}30.88 \\
{[26.80-35.28]}\end{array}$ & $\begin{array}{c}7.35 \\
{[5.25-10.17]}\end{array}$ & 1.46 & \\
\hline$>24$ & 101 & $\begin{array}{c}51.49 \\
{[41.33-61.55]}\end{array}$ & $\begin{array}{c}37.62 \\
{[28.18-47.82]}\end{array}$ & $\begin{array}{c}10.89 \\
{[5.56-18.65]}\end{array}$ & [1.03-2.07] & 0.03 \\
\hline \multicolumn{7}{|l|}{ Smoking status } \\
\hline Nonsmoker & 496 & $\begin{array}{c}60.08 \\
{[55.61-64.40]}\end{array}$ & $\begin{array}{c}31.85 \\
{[27.81-36.18]}\end{array}$ & $\begin{array}{c}8.06 \\
{[5.84-10.91]}\end{array}$ & 0.99 & \\
\hline Smoker & 81 & $\begin{array}{c}59.26 \\
{[23.24-44.68]}\end{array}$ & $\begin{array}{c}33.33 \\
{[23.24-44.68]}\end{array}$ & $\begin{array}{c}7.41 \\
{[2.77-15.43]}\end{array}$ & [0.66-1.49] & 0.93 \\
\hline Total & 577 & $\begin{array}{c}59.97 \\
{[55-83-63.97]}\end{array}$ & $\begin{array}{c}32.06 \\
{[28.30-36.07]}\end{array}$ & $\begin{array}{c}\mathbf{7 . 9 7} \\
{[5.95-10.57]}\end{array}$ & & \\
\hline
\end{tabular}

$\mathrm{N}$ - number of cases; OR - odds ratio; CI - confidence interval

EC appears to be less harmful to almost $60 \%$ of students, mostly in the age group $\leq 24(61.76 \%$ vs $51.49 \%$; OR $=1.46 ; 95 \%$ CI: $1.03-2.07)$. More than $32 \%$ of students consider EC as equally harmful and $8 \%$ even more harmful (Table 2).

The opinion of students about the addiction of EC did not differ significantly in any of the monitored categories; $41.2 \%$ of students considered EC as less addictive, $49 \%$ as equally addictive and nearly $10 \%$ more addictive than conventional cigarettes (Table 3 ).

Table 4. Perception of EC addiction comparing to classical cigarettes (bivariate analysis)

\begin{tabular}{|c|c|c|c|c|c|c|}
\hline \multirow[b]{2}{*}{ Characteristics } & \multirow[b]{2}{*}{$\mathbf{N}$} & \multicolumn{3}{|c|}{ Opinion about addiction \% [95\% CI] } & \multicolumn{2}{|c|}{ Bivariate analysis } \\
\hline & & $\begin{array}{c}\text { Less } \\
\text { addictive }\end{array}$ & $\begin{array}{c}\text { Equally } \\
\text { addictive }\end{array}$ & $\begin{array}{c}\text { More } \\
\text { addictive }\end{array}$ & $\begin{array}{c}\text { OR } \\
{[95 \% \mathrm{CI}]}\end{array}$ & p-value \\
\hline \multicolumn{7}{|l|}{ Gender } \\
\hline Women & 415 & $\begin{array}{c}40.72 \\
{[35.98-45.64]}\end{array}$ & $\begin{array}{c}50.36 \\
{[45.45-55.27]}\end{array}$ & $\begin{array}{c}8.42 \\
{[6.43-12.18]}\end{array}$ & 1.07 & \\
\hline Men & 162 & $\begin{array}{c}42.59 \\
{[34.8-50.59]}\end{array}$ & $\begin{array}{c}45.06 \\
{[37.25-55.06]}\end{array}$ & $\begin{array}{c}12.35 \\
{[7.71-18.42]}\end{array}$ & [0.80-1.43] & 0.20 \\
\hline \multicolumn{7}{|l|}{ Residence } \\
\hline Slovak & 486 & $\begin{array}{c}40.74 \\
{[36.36-45.27]}\end{array}$ & $\begin{array}{c}50.00 \\
{[45.77-54.53]}\end{array}$ & $\begin{array}{c}9.26 \\
{[6.90-12.28]}\end{array}$ & 1.05 & \\
\hline Abroad & 91 & $\begin{array}{c}43.96 \\
{[33.56-54.75]}\end{array}$ & $\begin{array}{c}42.86 \\
{[32.53-53.66]}\end{array}$ & $\begin{array}{c}13.19 \\
{[7.00-21.90]}\end{array}$ & [0.73-1.49] & 0.20 \\
\hline \multicolumn{7}{|l|}{ Age } \\
\hline$\leq 24$ & 476 & $\begin{array}{c}40.97 \\
{[36.54-45.55]}\end{array}$ & $\begin{array}{c}49.37 \\
{[44.80-53.95]}\end{array}$ & $\begin{array}{c}9.66 \\
{[7.23-12.77]}\end{array}$ & & \\
\hline$>24$ & 101 & $\begin{array}{c}42.57 \\
{[32.79-52.81]}\end{array}$ & $\begin{array}{c}46.53 \\
{[36.55-56.73]}\end{array}$ & $\begin{array}{c}10.86 \\
{[5.56-18.65]}\end{array}$ & $\begin{array}{c}0.99 \\
{[0.70-1.41]}\end{array}$ & 1.00 \\
\hline
\end{tabular}




\begin{tabular}{ccccccc} 
Nonsmoker & 496 & 40.52 & 50.60 & 8.87 & & \\
& & {$[36.19-45.00]$} & {$[46.12-55.08]$} & {$[6.59-11.81]$} & 1.11 & 0.55 \\
Smoker & 81 & 45.68 & 38.27 & 16.05 & {$[0.77-1.59]$} & \\
& & {$[34.56-57.13]$} & {$[27.69-49.74]$} & {$[8.83-25.88]$} & & \\
\hline \multirow{2}{*}{ Total } & \multirow{2}{*}{577} & 41.25 & 48.87 & 9.88 \\
& & {$[37.22-45.40]$} & {$[44.73-53.03]$} & {$[7.63-12.68]$} & & \\
\hline
\end{tabular}

$\mathrm{N}$ - number of cases; $\mathrm{OR}$ - odds ratio; $\mathrm{CI}$ - confidence interval

About $55.6 \%$ of students think they do not get enough education on ATP and EC during their medical study, with a statistically significant intersexual difference (47.53\% males vs $58.80 \%$ females; OR $0.65,95 \%$ CI $0.49-0.85), 48.5 \%$ of foreign and $58.4 \%$ of Slovak students do not have an idea about the EC content.

Table 5. Sample characteristics and cessation intervention (bivariate analysis)

\begin{tabular}{|c|c|c|c|c|c|c|}
\hline \multirow[b]{2}{*}{ Characteristics } & \multirow[b]{2}{*}{$\mathbf{N}$} & \multicolumn{3}{|c|}{ Receiving enough training \% $[95 \% \mathrm{CI}]$} & \multicolumn{2}{|c|}{ Bivariate analysis } \\
\hline & & Agree & Neutral & Disagree & $\begin{array}{c}\text { OR } \\
{[95 \% \mathrm{CI}]}\end{array}$ & p-value \\
\hline \multicolumn{7}{|l|}{ Gender } \\
\hline Women & 415 & $\begin{array}{c}17.35 \\
{[13.90-21.42]}\end{array}$ & $\begin{array}{c}23.86 \\
{[19.86-28.31]}\end{array}$ & $\begin{array}{c}58.80 \\
{[53.88-63.55]}\end{array}$ & 0.65 & \multirow{2}{*}{0.002} \\
\hline Men & 162 & $\begin{array}{c}26.54 \\
{[19.92-34.04]}\end{array}$ & $\begin{array}{c}25.93 \\
{[19.37-33.39]}\end{array}$ & $\begin{array}{c}47.53 \\
{[39.04-55.51]}\end{array}$ & [0.49-0.85] & \\
\hline \multicolumn{7}{|l|}{ Residence } \\
\hline \multirow[b]{2}{*}{ Abroad } & 486 & $\begin{array}{c}19.75 \\
{[16.36-23.63]}\end{array}$ & $\begin{array}{c}23.87 \\
{[20.20-27.96]}\end{array}$ & $\begin{array}{c}56.38 \\
{[51.83-60.82]}\end{array}$ & \multirow{2}{*}{$\begin{array}{c}0.98 \\
{[0.63-1.24]}\end{array}$} & \multirow{2}{*}{0.76} \\
\hline & 91 & $\begin{array}{c}20.88 \\
{[13.06-30.67]}\end{array}$ & $\begin{array}{c}27.47 \\
{[18.63-37.83]}\end{array}$ & $\begin{array}{c}51.65 \\
{[40.93-62.26]}\end{array}$ & & \\
\hline \multicolumn{7}{|l|}{ Age } \\
\hline$\leq 24$ & 476 & $\begin{array}{c}19.12 \\
{[15.74-23.00]}\end{array}$ & $\begin{array}{c}25.21 \\
{[21.42-29.41]}\end{array}$ & $\begin{array}{c}55.67 \\
{[51.08-60.18]}\end{array}$ & 1.12 & \multirow{2}{*}{0.34} \\
\hline$>24$ & 101 & $\begin{array}{c}23.76 \\
{[15.86-33.26]}\end{array}$ & $\begin{array}{c}20.79 \\
{[13.36-30.01]}\end{array}$ & $\begin{array}{c}55.45 \\
{[45.22-65.34]}\end{array}$ & [0.81-1.55] & \\
\hline \multicolumn{7}{|l|}{ Smoking status } \\
\hline Nonsmoker & 496 & $\begin{array}{c}19.35 \\
{[16.03-23.17]}\end{array}$ & $\begin{array}{c}25.81 \\
{[22.06-29.94]}\end{array}$ & $\begin{array}{c}54.84 \\
{[50.34-59.26]}\end{array}$ & 1.00 & \multirow{2}{*}{0.84} \\
\hline Smoker & 81 & $\begin{array}{c}23.46 \\
{[14.75-34.18]}\end{array}$ & $\begin{array}{c}16.05 \\
{[8.83-25.88]}\end{array}$ & $\begin{array}{c}60.49 \\
{[49.01-71.19]}\end{array}$ & [0.70-1.45] & \\
\hline Total & 577 & $\begin{array}{c}19.93 \\
{[16.79-23.48]}\end{array}$ & $\begin{array}{c}\mathbf{2 4 . 4 4} \\
{[21.03-28.19]}\end{array}$ & $\begin{array}{c}\mathbf{5 5 . 6 3} \\
{[51.47-59.72]}\end{array}$ & & \\
\hline
\end{tabular}

$\mathrm{N}$ - number of cases; OR - odds ratio; CI - confidence interval

\section{Discussion}

The results of our study indicate a high prevalence of current (14\%), and past smokers among medical students (19.3\%), every fifth is an ex-smoker, every seventh student is a current smoker. 
Similar findings were obtained about experiences with ECs, that currently uses $13.5 \%$ medical students, with a statistically significant intersexual difference.

In a study conducted at New York University out of a total of 431 students who completed the questionnaire, 64 students $(14.7 \%)$ reported being current users of tobacco or tobacco products, including cigarettes $(n=17 ; 3.9 \%)$ and alternative tobacco products (ATP) $(n=21 ; 4.8 \%)$ [19].

Overall population data on the number of smokers are probably inaccurate and, due to different sources, also very different, as they are mainly obtained by the questionnaire methods on a limited population. In compliance with the Slovak Cardiovascular Program (1978 - 1988), 44\% of men and $12.8 \%$ of women smoked in Slovakia in the given period. According to the Statistical Office of the Slovak republic in the year 1996, $40 \%$ of men and $17 \%$ of women smoked and according to WHO data in $1998,44.1 \%$ of men and $14.7 \%$ of women smoked in Slovakia [20].

According to the WHO Report on the Global Tobacco Epidemic [21], the age-standardized prevalence estimate in Slovakia for tobacco smoking among adults in 2009 was $23 \%$. In addition, according to the 2007 Global Youth Tobacco Survey (GYTS), more than 50\% of children in Slovakia between the ages of 13 and 15 were exposed to ETS [22,23].

According to the WHO (Tobacco and Health Education Survey), the prevalence of adult tobacco smokers in Slovakia in 2004 was $29 \%, 24 \%$ of women and 34\% of men [24].

According to the last available results from Eurobarometer in 2017, there are 26\% of current smokers in the Slovak Republic. When comparing these results to those collected in 2014, the overall proportion of daily smokers has remained the same in the Member States, proportions have increased in Slovakia ( +5 percentage points). The average number of cigarettes smoked per day by daily smokers varies across countries, the average number of cigarettes smoked exceeds 10. In most countries, change has been minimal since the last survey. Slovakia stands out for a significant increase in the average number of cigarettes smoked daily, up by 2.8 since December 2014 (from 15.9 in 2014 to 18.7 in 2017 [25].

The traditional male dominance, typical of the adult population in most countries of the world, is slowly disappearing in the younger age groups in Europe and in the U.S. The number of smokers, especially young women, is increasing dangerously, which may have health implications for the entire population. Therefore, prevention programs should specifically target a group of girls [26].

Based on epidemiological data on smoking in children and adolescents, the prevalence of smoking of the adult population in the future, its characteristics, as well as the extent of health impacts, can be estimated.

EC consumption has increased considerably especially among youth, growing an astounding 900\% among high school students in the USA from 2011 to 2015 [11]. Data from several representative surveys in GB suggest that vaping prevalence among all adults in Great Britain has remained stable since 2015. In 2017 to 2018, estimates for prevalence were $5.4 \%$ to $6.2 \%$ for all adults, higher for smokers, with increasing experimentation and use of EC over time among youth [9]. An estimated 10.8 million people in the US used EC in 2018. The prevalence of e-cigarette use varied widely among states. The estimates were ranging from $3.1 \%$ to $7.0 \%$ [27].

According to Eastwood et al. [28] from the United Kingdom, EC vaping in young people is increasing but is largely limited to those who smoke classic cigarettes. Among young people (11 to 18 years of age) involved in the YouGoy online survey, EC usage increased significantly from $4.6 \%$ (2013) to $8.2 \%$ (2014). Among regular EC users vaping increased from $0.9 \%$ to $1.7 \%$.

Comparable data to our study were in the American study (National Youth Tobacco Survey, 2013). From 24,658 young people, only half of the youngsters have heard about EC. Of these, around $13 \%$ have already actively tested them and more than $4 \%$ still smoke [29].

Some studies in a number of countries (South Africa, Pakistani) have found that as many as $20 \%$ of medical students use ATPs [19].

In the YABS study performed on the sample of 15-19 years old youngsters in Bratislava we found out that the occurrence of CC smoking in the secondary school students' sample was almost $20 \%$; older students and students from vocational schools smoked significantly more. The experience with alternative tobacco products (ATP) (except EC) had $63.1 \%$ of students. There were no differences in 
the experience with EC vaping among age groups - a very high percentage (> $40 \%)$ in both groups (younger and older) [30].

Easier availability of the EC and its widespread distribution is accompanied by many controversial views. Since ENDS is on the market for a relatively short time compared to conventional cigarettes, there are still no known long-term health effects [7]. Significant increases in their use and increasing popularity among young people lead to concerns mainly from possible consequences. Therefore, it is important to explore trends in the perception and the use of not only regular cigarettes but also electronic cigarettes in this age group. The reasons for using EC in young adults are varied and are not limited to stopping smoking. Quit smoking is not the only reason to use EC by young adults [31].

A growing proportion of young people in the UK believe that vaping EC is as harmful as smoking tobacco. Eastwood et al. comparing 2013 and 2014 found that the number of young people who perceived EC as less harmful compared to conventional cigarettes decreased from $73.4 \%$ to $66.9 \%$, while the proportion of young people who considered as equally harmful, increased from $11.8 \%$ to $18.2 \%$ [28].

In a study by our NYU partners, American students shared the view that ATP, including EC, contributes less to the emergence and development of various diseases than conventional cigarettes. Users of other tobacco products, Caucasians and those students whose family members smoked were more likely to perceive EC as relatively safer [19].

ECs seem to be equally harmful to almost one-third of our medical students, two-thirds of students consider them to be less harmful, some students think they are even more harmful. Older students more often perceived EC more harmful compared to younger students.

Perception of EC as less harmful than conventional cigarettes was associated with increased EC use, including among cigarette-naive EC users [32]. According to some studies, there is evidence that dual use of CC and EC does not help smokers quit or reduce smoking [33] and some suggest that vaping has attracted millions of American teenagers into nicotine addiction and has led some to start smoking.

In our study, we also focused on observing students' opinions in terms of their perception of the degree of the addictiveness of electronic cigarettes compared to conventional cigarettes. The opinions of students did not differ significantly in any of the monitored categories; the majority of students thought they are equally addictive; slightly over $40 \%$ of students considered EC less addictive and one out of ten students more addictive than conventional cigarettes. About $55.6 \%$ of students think they do not get enough education on ATP and EC during their medical study, with a statistically significant intersexual difference ( $47.53 \%$ males vs $58.80 \%$ females; OR $0.65,95 \%$ CI $0.49-0.85), 48.5 \%$ of foreign and $58.4 \%$ of Slovak students do not have an idea about the EC content.

The EC remains a controversial topic, having both its opponents and supporters.

EC advocates argue that EC could help reduce the global risk of death attributed to conventional cigarette smoking, as well as reduce exposure to ETS [24, 28, 34]. They further proclaim that ECs are used almost exclusively as safer alternatives to classic tobacco products in classic cigarette smokers who seek to reduce or quit smoking completely and do not constitute a "gateway" to smoking initiation [35]. For now, the EC can hardly be considered safe for everybody, even if they have less harmful consequences than conventional cigarettes. It cannot be disputed against the assumptions of the harm reduction strategy for smokers and its supportive way of reducing the negative consequences of smoking [7]. Future research is needed to evaluate the long-term health outcomes and efficiency of EC with a greater discussion between patients and clinicians regarding this smoking cessation tool [36].

On the other hand, some risks from their use are evident. Non-combustible tobacco is not a totally harmless alternative, as it is also a risk factor for some health-related problems. Nicotine is a potent psychoactive drug that, when bound to specific acetylcholine receptors, causes the leaching of neurotransmitters, especially dopamine and hormones, followed by a reward for the smoker in terms of well-being and increased short-term performance. Any use of nicotine, and therefore smoking of EC, can be expected to cause dependence, both physical and mental, in most users [37, 38]. Given the 
rapid distribution of nicotine at inhalation exposure, nicotine can be expected to exert its vasomotor efficacy in smoking of EC through activation of the sympathetic nervous system and adrenal glands, which poses an increased risk especially in patients with cardiovascular disease [39]. An additional risk is associated with the possibility of an overdose. While a smoker gets an average of $1 \mathrm{mg}$ of nicotine from a conventional cigarette, e-cigarette cartridges contain about $18 \mathrm{mg}$, but also higher amounts of nicotine. A fatal dose for an adult is considered to be $30-60 \mathrm{mg}$, for a child $10 \mathrm{mg}$ nicotine [40].

In addition, while the long-term consequences of using EC not only for individuals but for society as a whole remain uncertain from a public health perspective, the Surgeon General's Report 2014 suggested that nicotine may have adverse effects o.i. for the development of the brain not only for children but also for young adults, the use of nicotine in any form is not safe for them and is not recommended [5,38,41].

Although several studies are currently underway, due to many methodological problems as well as other negative factors affecting the objectivity of the results - serious conflicts of interest of study implementers, lack of long-term follow-ups, small number of participants, inconsistencies and discrepancies in methodology, studies, no clear conclusions can be drawn about EC safety [7].

According to the Royal Colleague of Physicians' recommendations, it is important to encourage the use of non-tobacco nicotine products as much as possible to replace conventional smoking in order to protect the health of the population [35]. Several experts acknowledge that ENDS should be regulated as a source of nicotine, not as a tobacco product, but should be demonstrated to be safe and effective before being marketed. They should not be allowed where smoking is not allowed until the exact composition of their emissions and the consequent potential health consequences are not known $[7,32,40]$.

However, this study has several strengths and limitations. The limitations of the study are crosssectional design, on an online questionnaire basis with all its biases and misclassifications, the relatively small sample size and the low response rate.

The strengths of our study are the homogeneity of the group concerning age, study interests, level of knowledge, and health awareness. This can help to reduce confounding, but it might limit the generalizability of the results to the Slovak or European population. The questionnaire itself had an educational potential and helped us to elucidate educational gaps and to develop missing learning objectives in the curricula. The fact, that such data on the use of EC and ATPs among Slovak students are not present in any accessible international database and peer-reviewed international journal makes the study novel and valuable.

Present studies suggest that some Heat-not-Burn tobacco products have the potential to be a reduced risk product for public health compared to $\mathrm{CC}$, considering indirectly the potential effects on the chronic non-communicable diseases and ETS exposure.

It is generally accepted that smoking habits are mainly developed in young people during adolescence and early adulthood. Tobacco prevention programs targeting adolescents should emphasize the risks of using not only CC, but also ATP and general accessibility of ATPs should be better regulated to prevent potential harmful consequences of adolescent poly tobacco use [42].

\section{Conclusions}

The results show the high consumption of tobacco products and the lack of knowledge and awareness of the harmful effects of electronic cigarettes (ECs) and alternative tobacco products (ATPs) among medical students in Bratislava. ECs currently uses $13.5 \%$ medical students, with a statistically significant intersexual difference and the difference between Slovak and foreign medical students foreign students were more likely to smoke ECs. Smokers of conventional cigarettes used to vape more than non-smokers.

Medical students supposed to have enough of proper knowledge to prepare for their role. A concerning percentage of surveyed medical students still use different tobacco products, including ECs. It seems they do not have enough knowledge, education, and cessation counseling skills to provide proper information about this topic to patients. Physicians should play an important role in 
preventing and counseling about risk factors of different non-communicable diseases. They can help especially the young generation with applying principles of a healthy lifestyle in disease prevention including not to initiate smoking but also could help patients treating addiction to smoking. The information on the new tobacco products and effective smoking cessation should be added into the curricula of the future physicians and to the preventive programs and public health policies.

Our study emphasizes the need for intervention in this field at medical faculties and for support of further monitoring and comparing results in larger surveys in Slovakia and the other countries. Our findings merit further consideration from research and policy perspectives as to the ongoing lack of EC regulation.

Author Contributions: J.B., L.A., and M.W. conceived and designed the project; J.B., L.A and D.V. wrote the manuscript; J.B., D.V., L.A. and A.F. collected and analyzed the data; L.A., J.J., J.B. and M.W. provided critical revision of the manuscript; J.B., A.F., D.V. and L.A. performed literature search and drafted sections of the manuscript; J.S., B.K. and L.A. were responsible for funding acquisition and project administration; J.J., L.A. and M.W. provided critical revision of the manuscript and did the language, style, and spell-check; All authors have approved the submitted version. All authors have read and agreed to the published version of the manuscript.

Funding: The research was partially supported by the grant Y.A.B.S. (Youth and Parents Behavioral Survey in Slovakia) O-15-101-/0001-00.

Conflicts of Interest: The authors declare no conflict of interest.

\section{References}

1. World Health Organization. WHO global report on trends in the prevalence of tobacco use 2000-2025, $3^{\text {rd }}$ ed.; World Health Organization: Geneva, Switzerland, 2019. Available online: https://www.who.int/publications-detail/who-global-report-on-trends-in-prevalence-of-tobacco-use-20002025-third-edition (accessed on 2 December 2019).

2. U.S. Department of Health \& Human Services. The Health Consequences of Smoking-50 Years of Progress. A Report of the Surgeon General; U.S. Department of Health \& Human Services: Rockville MD, U.S., 2014. Available online: https://www.ncbi.nlm.nih.gov/books/NBK179276/pdf/Bookshelf_NBK179276.pdf (accessed on 6 December 2019).

3. World Health Organization. Tobacco. World Health Organization: Geneva, Switzerland, 2019. Available online: https://www.who.int/news-room/fact-sheets/detail/tobacco (accessed on 12 December 2019)

4. European Commission. Special Eurobarometer 458: Attitudes of Europeans towards tobacco and electronic cigarettes. 2017. Available online: http://ec.europa.eu/COMMFrontOffice/PublicOpinion (accessed on 2 December 2019).

5. King, B.; Pechacek, T.; Mariolis, P. Best Practices for Comprehensive Tobacco Control Programs; Centers for Disease Control and Prevention: Atlanta, U.S., 2014. Available online: https://www.cdc.gov/tobacco/stateandcommunity/best practices/pdfs/2014/comprehensive.pdf (accessed on 30 November 2019).

6. La Torre, G., Mipatrini, D. Country-level correlates of e-cigarette use in the European Union. Int J Public Health 2016, 61, 269-275. https://doi:10.1007/s00038-016-0792-1

7. Pisinger, C.; Døssing, M. A systematic review of health effects of electronic cigarettes. Prev. Med. 2014, 69, 248-260. doi:10.1016/j.ypmed.2014.10.009

8. ASA. 33 Electronic cigarettes. ASA Press Office 2019. Available online: https://www.asa.org.uk/type/broadcast/code_section/33.html (accessed on 4 December 2019).

9. Public Health England. Guidance E-cigarettes: regulations for consumer products. Medicines and Healthcare products Regulatory Agency. 2019. Available online: https://www.gov.uk/guidance/ecigarettes-regulations-for-consumer-products (accessed on 2 December 2019).

10. Gray, N.; Halstead, M.; Gonzalez-Jimenez, N.; Valentin-Blasini, L.; Watson, C.; Pappas, R.S. Analysis of Toxic Metals in Liquid from Electronic Cigarettes. Int J Environ Res Public Health 2019, 16, 4450. doi:10.3390/ijerph16224450

11. U.S. Department of Health and Human Services. E-Cigarette Use Among Youth and Young Adults. A Report of the Surgeon General. Centers for Disease Control and Prevention: Atlanta, U.S., 2016. Available online: 
https://www.cdc.gov/tobacco/data statistics/sgr/e-cigarettes/pdfs/2016 sgr entire report 508.pdf (accessed on 7 December 2019)

12. The National Academies of Sciences, Engineering and Medicine. Public health consequences of e-cigarettes. Consensus study report. The National Academies Press: Washington, DC., U.S., 2018. Available online: https://www.nap.edu/catalog/24952/public-health-consequences-of-e-cigarettes (accessed on 4 December 2019).

13. Gualano, M.R.; Passi, S.; Bert, F.; La Torre, G.; Scaioli, G. Siliquini, R. Electronic cigarettes: assessing the efficacy and the adverse effects through a systematic review of published studies. J Public Health (Oxf) 2015, 37, 488-497. doi:10.1093/pubmed/fdu055

14. Schraufnagel, D.E.; Blasi, F.; Drummond, M.B.; Lam, D.C.L; Latif, E.; Rosen, M.J. et al. Electronic cigarettes. A position statement of the forum of international respiratory societies. Am J Respir Crit Care Med 2014, 190, 611-618. https://doi:10.1164/rccm.201407-1198PP

15. Joseph K. Electronic Cigarettes: An Evidence-Based Analysis. Prof Case Manag 2015, 20, $251-259$. doi:10.1097/NCM.0000000000000112

16. Abafalvi, L.; Penzes, M.; Urban, R.; Foley, K.L.; Kaan, R.; Kispelyi, B.; Hermann, P. Perceived health effects of vaping among Hungarian adult e-cigarette-only and dual users: a cross-sectional internet survey. BMC Public Health 2019, 19, 302. doi:10.1186/s12889-019-6629-0

17. Centers for Disease Control and Prevention. CDC Director's Statement on the first death related to the outbreak of severe lung disease in people who use e-cigarette or "vaping" devices. 2019. Available online: https://www.cdc.gov/media/releases/2019/s0823-vaping-related-death.html (accessed on 11 January 2020).

18. Krishnasamy, V.P; Hallowell, B.D; Ko, J.Y, et al. Update: Characteristics of a Nationwide Outbreak of Ecigarette, or Vaping, Product Use-Associated Lung Injury - United States, August 2019-January 2020. MMWR Morb Mortal Wkly Rep 202, 69, 90-94. doi:10.15585/mmwr.mm6903e2

19. Zhou, S.; Van Devanter, N.; Fenstermaker, M.; Cawkwell, P.; Sherman, S.; Weitzman, M. A Study of the Use, Knowledge, and Beliefs About Cigarettes and Alternative Tobacco Products Among Students at One U.S. Medical School. Acad Med 2015, 90, 1713-1719. doi:10.1097/ACM.0000000000000873

20. Riecansky, I.; Egnerova, A. Implementation and results of the cardiovascular program in the Slovak Republic, 1st ed.; Institute of Health Education: Bratislava, Slovakia, 1990; pp. 16-24. (in Slovak) ISBN Z-5945/88-B/11-04

21. World Health Organization. WHO Report on the Global Tobacco Epidemic, Warning about the dangers of tobacco. World Health Organization: Geneva, Switzerland, 2011. Available online: https://apps.who.int/iris/bitstream/handle/10665/44616/9789240687813_eng.pdf;jsessionid=DEB6901487BE 2846DB0DE080AA6C0134?sequence=1 (accessed on 20 November 2019).

22. Baska, T. Prevencia uzivania tabaku u skolskej mladeze: Prevention of tobacco abuse in school youth: Results of the Global Youth Tobacco Survey 2007 in Slovakia. 1st ed.; National Coalition for Tobacco Control in Slovakia: Martin, Slovakia, 2008; pp. 25-45 (in Slovak). ISBN 978-80-969767-1-3

23. Babjakova, J.; Sevcikova, L.; Jurkovicova, J.; Vondrova, D.; Krajcova, D.; Sekretar, S. et al. E-Cigarettes Experiences, Opinions and Attitudes among Medical Students. Zivotné podmienky a zdravie. UVZSR: Bratislava, Slovakia, 2016; pp. 191-198 (in Slovak).

24. World Health Organization. WHO Report on the Global Tobacco Epidemic, 2017: Monitoring Tobacco Use and Prevention Policies. World Health Organization: Geneva, Switzerland, 2017. Available online: https://www.who.int/tobacco/mpower/monitor/en/ (accessed on 1 December 2019).

25. European Commission. Eurobarometer 2017. Special Eurobarometer 458 "Attitudes of Europeans towards tobacco and electronic cigarettes" Summary. EU Publications: European Union, 2018. Available Online: https://op.europa.eu/en/publication-detail/-/publication/c2dc8256-0af0-11e8966a/01aa75ed71a1/language-en (accessed on 29 November 2019).

26. Baska, T.; Warren, Ch.; Baskova, M.; Jones, N. Prevalence of youth cigarette smoking and selected social factors in 25 European countries: findings from the Global Youth Tobacco Survey. Int J Public Health 2009, 439-445. ISSN 1661-8556

27. Mirbolouk, M; Charkhchi, P.; Kianoush, Sina Kianoush, S.; S M Iftekhar Uddin, S.M.U.; Orimoloye, O.A. et al. Prevalence and Distribution of E-Cigarette Use Among U.S. Adults: Behavioral Risk Factor Surveillance System, 2016. Ann Intern Med 2018, 169, 429-438. doi:10.7326/M17-3440

28. Eastwood, B.; Dockrell, M. J.; Arnott, D.; Britton, J.; Cheeseman, H.; Jarvis, M. J.; McNeill, A. Electronic cigarette use in young people in Great Britain 2013-2014. Public Health 2015, 129, 1150-1156. doi:10.1016/j.puhe.2015.07.009 
29. Arrazola, R.A.; Singh, T.; Corey, C.G.; Husten, C. G.; Neff, L. J.; Benjamin J Apelberg, B.J. et al. Tobacco use among middle and high school students - United States, 2011-2014. MMWR Morb Mortal Wkly Rep 2015, 64, 381-385.

30. Babjakova, J.; Vondrova, D.; Jurkovicova, J.; M Samohyl, M.; Filova, A.; Janko, Z.; Stefanikova, Z.; Hirosova, K.; Weitzman, M.; Argalasova, L. Risk behavioral survey in the sample of Slovak adolescents. Bratisl Lek Listy 2019, 120, 899-907. doi:10.4149/BLL2019151

31. Kinouani, S.; Leflot, C.; Vanderkam, P.; Auriacombe, M.; Langlois, E.; Tzourio, C. Motivations for using electronic cigarettes in young adults: A systematic review. Substance abuse 2019, 1-8. doi: 10.1080/08897077.2019.1671937

32. Amrock, S.M.; Zakhar, J.; Zhou, S.; Weitzman, M. Perception of E-cigarettes' Harm and Its Correlation With Use Among U.S. Adolescents. Nicotine Tob Res 2015, 17, 330-336. doi:10.1093/ntr/ntu156

33. Manzoli, L.; Flacco, M.E.; Fiore, M.; La Vecchia, C.; Marzuillo, C.; Gualano, M.R. et al. Electronic Cigarettes Efficacy and Safety at 12 Months: Cohort Study. PLoS One 2015, 10, e0129443. doi:10.1371/journal.pone.0129443

34. Hajek, P.; Etter, J.F.; Benowitz, N.; Eissenberg, T.; McRobbie, H. Electronic cigarettes: review of use, content, safety, effects on smokers and potential for harm and benefit. Addiction 2014, 109, 1801-1810. doi:10.1111/add.12659

35. Royal College of Physicians. Nicotine without smoke: Tobacco harm reduction. A Report by the Tobacco Advisory Group of the Royal College of Physicians UK, 2016. Available from: https://www.rcplondon.ac.uk/projects/outputs/nicotine-without-smoke-tobacco-harm-reduction-0. (accessed on 8 January 2020)

36. Worku, D.; Worku, E. A narrative review evaluating the safety and efficacy of e-cigarettes as a newly marketed smoking cessation tool. SAGE Open Medicine 2019, 7, 1-10. doi:10.1177/2050312119871405

37. Cobb, C. O.; Weaver, M. F.; Eissenberg, T. Evaluating the acute effects of oral, non-combustible potential reduced exposure products marketed to smokers. Tob. Control 2010, 19, 367-373. doi:10.1136/tc.2008.028993

38. Etter, J. F.; Bullen, C. Electronic cigarette: users profile, utilization, satisfaction and perceived efficacy. Addiction 2011, 106, 2017-2028. doi:10.1111/j.1360-0443.2011.03505.x

39. Hruba, D. What are electronic cigarettes for? Current knowledge for practice. General practitioner, 2012, 92, 449-451 (in Czech).

40. Kralikova, E.; Jezek, M. et al. Electronic cigarettes. Cas. Lek. ces. 2012, 151, 208-210 (in Czech).

41. Harrell, P. T.; Simmons, V. N.; Correa, J. B.; Padhya, T. A.; Brandon, T. H. Electronic Nicotine Delivery Systems ("E-cigarettes") Review of Safety and Smoking Cessation Efficacy. Otolaryngol Head Neck Surg 2014, 151, 381-393. doi:10.1177/0194599814536847

42. Penzes, M.; Foley, K.L.; Nadaşan, V.; Paulik, E.; Abram, Z.; Urban, R. Bidirectional associations of ecigarette, conventional cigarette and waterpipe experimentation among adolescents: A cross-lagged model. Addict Behav 2018, 80, 59-64. https://doi.org/10.1016/j.addbeh.2018.01.010 